\title{
The dissemination of economic ideas: introduction
}

\section{Heinz D. Kurz, Tamotsu Nishizawa and Keith Tribe ${ }^{1}$}

In March 2009 a joint meeting of the Japanese and European Societies for the History of Economic Thought was held in Tokyo and Kyoto, dedicated to the theme of 'The Dissemination of Economic Ideas'. ${ }^{2}$ This volume presents selected papers from that conference, marking a significant stage in our growing understanding of the manner in which the ebb and flow in the development of national traditions of economic thought has been affected by the interaction of internal and external factors. We should also note that the possibility of discussing the dissemination process in such a context was itself made possible by the existence of a European society which has over the past decade and a half provided a framework for regular meetings of scholars who are themselves also members of national bodies. ${ }^{3}$ While the subject matter of this collection reaches back to the seventeenth century, regular interchanges of the kind represented by the Tokyo and Kyoto meetings go back no more than 20 or 30 years. And so this book places an explicit agenda - study of the dissemination of economic ideas over a period of four centuries - within an implicit framework which is, relatively speaking, quite new. This introduction is directed to both of these issues, but begins necessarily from the intentions framing the March 2009 meetings. ${ }^{4}$

Consideration of the propagation and dissemination of economic ideas comes naturally to Japanese scholars, for the Meiji Restoration of 1867 inaugurated a period of rapid change for Japanese society, characterized by the extensive importation of ideas and institutions from the West. This opening of Japan to the West coincided with the ending of the American Civil War and the creation of an independent Germany; during the later nineteenth century these became the most dynamic world economies and consequently important influences upon Japanese development. Social and cultural reform in Japan was heavily influenced by German models; for example, the Imperial University Act of 1886 followed the Prussian model and Tokyo Imperial University was inaugurated, then in 1896 an association modelled on the Verein für Socialpolitik was founded, while 
the forerunners of Hitosubashi University itself drew heavily on the curriculum of the new German Handelshochschulen. ${ }^{5}$ This period, in which modernization implied the importation of Western models, came to an end in the later 1920s. From the early 1930s onwards Japan sought to exploit its new-found industrial and military power to establish itself as the dominant Asian power, a course which brought the invasion of China in 1937 and ultimately led Japan into the Second World War, in which the United States became its enemy and Germany its ally. The ensuing defeat of Japan by United Nations ${ }^{6}$ forces in August 1945 led to occupation by the United States and a continuation of the economic modernization initiated in the later nineteenth century. This succeeded in transforming Japan into a global economic power which, while international in orientation, remains culturally distinctive, despite the social, political and economic turmoil of its development during the century following the Meiji Restoration.

Against such a background it was for many years accepted by both Japanese and non-Japanese scholars that the development of modern economics in Japan has been dominated by the assimilation firstly of European ideas and institutions, and subsequently by those of the United States (Sugihara and Tanaka, 1998). However, as our understanding of the diffusion of economics has developed during the past two or three decades, this simple story of the transmission and reception of modern economics has been progressively modified. Simple citation of one economist by another, or lack of such citation, is clearly inadequate. Access or lack of such access to literature through translation provides many insights, ${ }^{7}$ as does knowledge of library holdings. ${ }^{8}$ But while the catalogue of Adam Smith's library (Mizuta, 2000), together with that of the Edinburgh Advocates' Library, gives us a clear idea of what he actually read above and beyond what is cited in his writings, we still have to recognize that his works passed into the hands of readers of variable consistency, ability and understanding. And so while, for example, scholars still debate the nature of Smith's allusion to an 'invisible hand', generations of readers have confidently assumed that this is little more than a central metaphor for the market mechanism built upon an allusion to Mandeville's distinction of private vices and public benefits. Historians are aware that such a view is faulty, but that does not prevent repetition of the idea.

Even if we restrict our attention to the dissemination of Adam Smith's ideas, it quickly becomes apparent that in the process of transmission his economic ideas can easily become transformed into platitudes which in turn shape 'common knowledge' of his work. This is not merely a matter of 'expert' versus 'lay' readings of a text. The history of economics is a trail littered with examples of successive and self-reinforcing misreadings on the part of economists who might otherwise have been thought 
to 'know better', as the sorry history of the 'Keynesian Revolution' also testifies. ${ }^{9}$ And so although it might appear that the primary object in studying the dissemination of ideas is to track the flow of ideas from one period to the next, and from one part of the world to another, much as we might monitor the migratory patterns of barnacle geese,$^{10}$ there is in fact an inherent instability in the object of our attention. For concepts are not invariant objects that are moved around like so many pieces of Lego, always the same shape and colour, no matter to what use they are put. And the history of economics should not be conceived as a means of rectifying this natural tendency for ideas to transmute through repetition, but instead adopt this process of transformation as an object of study in itself.

Consequently, the history of the dissemination of economic ideas becomes a history of the flux of economic ideas, rendering any easy generalization difficult, even impossible. For example, given the American occupation of post-war Japan and the fact that this period was characterized by the development of an international economics dominated by American textbooks and teaching, we might conclude that the combination of these circumstances would necessarily have served to reshape the thinking of Japanese economists along American lines. But this did not in general happen; in fact, during the post-war period Marxist economics flourished in Japan as nowhere else outside the Soviet Union and its satellite states (Akama, 2000), alongside some cross-fertilization and international dissemination of Japanese non-Marxist economics (Yagi, 2000). There are good institutional reasons for both of these trends, but this only underlines the fact that one cannot ignore the context into which ideas are introduced and domestically recycled. The Japanese experience of 'reception' also highlights the fact that choices can be made: while some scholars turned to German models in the later nineteenth century, others opted for a more liberal tradition and turned to Mill, Fawcett, Marshall and Pigou. And the history of translation also complicates assumptions we might make about 'transmission' and 'reception': the writings of Walras and Gossen were translated into Japanese respectively 50 and 80 years before their first translation into English. Partly at least as a consequence of this last development, general equilibrium theory took a firm hold among Japanese economists during the 1930s, so much so that it has been argued that Japan here was in advance of developments among Anglophone economists (Nishizawa and Ikeo, 2008). ${ }^{11}$

We could turn the argument with which we started on its head, and suggest that far from Japan being a clear case of dissemination and influence, what we see in Japan is only a more obvious case of a universal phenomenon in the history of economic thought. It is the scale of the initial cultural divide between Japan and the West, and the 'late start' of Japan's 'modernization', that has lent the Japanese case unusual clarity, not least 
to the Japanese themselves. But the same mixed process of dissemination and lack of response has characterized the flow of ideas around Europe over the last 200 years. Coming back to Adam Smith again, it is today too easily forgotten that English only became a world language in the twentieth century, before which French and German were the prevailing world languages. In nineteenth-century Europe, Adam Smith's Wealth of Nations was indeed widely read - but in French translation, which as Karl Marx's notebooks show is how he read Smith. During the nineteenth century Smith was widely read not primarily as part of 'English' classical economics, but rather in the context of contemporary French liberal economists such as Joseph Garnier and, indeed, Frédéric Bastiat.

While Japanese scholars might therefore have a special interest in the process of the dissemination of economic ideas, this is no less an issue for European historians. The early foundation of the Japanese Society for the History of Economic Thought (JSHET) reflects the long-standing interest among Japanese economists in the historical development of their discipline and its discourse. ${ }^{12}$ The American equivalent was not founded until $1974,{ }^{13}$ since when several national societies have been created. The European Society for the History of Economic Thought was a departure from this national model since it aimed to bring together scholars many of whom were already members of their national bodies, but who had a common interest in a more international perspective for their work. In this respect, it is worth noting that the international project on the institutionalization of political economy developed during the $1980 \mathrm{~s}^{14}$ was the first large-scale international collaborative project among historians of economic thought, and that it relied initially for its administration on the resources of the King's College Cambridge Research Centre and not on any existing national association. While the European Society is conceived as a body to promote the scholarship of its members, rather than to undertake projects on its own account, its inherent international composition makes it a natural vehicle for consideration of the international dissemination of economic ideas. Linked to Japanese scholars in the sister Japanese Society who are more conscious than most of the impact of this process, this makes the topic chosen for the joint meeting in 2009 a more than appropriate choice.

The papers selected for publication here are chronologically ordered, although this apparently simple editorial approach itself reveals important aspects of the phasing of the dissemination process. The first chapter relates to the early seventeenth century: Bertram Schefold's account of the work of Kaspar Klock and its connection with the Salamanca School. This is however not a simple account of dissemination and reception, not least because this process is usually conceived as a form of exchange 
between nation-states and their national languages. Klock was writing at the time of the Thirty Years' War, when the European political space was being recast, and he wrote in Latin, which was still a transnational language. Consequently Schefold's study demonstrates the manner in which Klock drew on the wide array of sources available to him in the European space, without regard to national languages or political boundaries. Reading Klock in this way makes it possible to establish the nature of his sources; Schefold appends a translation of Klock's account of Japan, for which Klock drew on reports by Jesuit fathers.

Seiichiro Ito's chapter takes us to the late seventeenth century and the rivalry between European powers. Davenant, being an Englishman, sought to promote the strength of Britain; Spain was no longer the power that it had been, and the hostilities with the Netherlands having been resolved through the recruitment of a Dutch monarch, the prime rival was France, which threatened to overturn the balance of emerging powers. But this did not prevent Davenant drawing upon French sources in creating arguments regarding the restoration of British power, which he treated as primarily a fiscal issue. Ito demonstrates that Davenant drew heavily upon Richelieu's Testament politique, so that much of his argument depends not, as previously assumed, upon a Florentine political tradition embodied by Machiavelli's treatise, but instead on the more immediate and relevant practical issues of governance and power in seventeenth-century France.

Cunha tracks the reception of Cameralistic principles and Polizei in eighteenth-century Portugal together with its empire. Here there is no direct link through translation besides the publication of a Portuguese version of Bielfeld's Institutions politique, a work which reflects French rather than German conceptions of 'police'. However, there is a connection through translations into Spanish, a language accessible to the Portuguese, whose rulers would in any case have had command of the French language. Cunha shows how the process of fiscal and administrative reform in the wake of the Lisbon earthquake drew on the models advocated in the German states, rather than in France, and suggests that here an indirect process of diffusion was at work.

With Yukihiro Ikeda's chapter we move into the nineteenth century and the influence on the textbooks of Karl Heinrich Rau and Wilhelm Roscher of English classical economics. It has long been recognized that both writers synthesized their writings from many sources without great regard to the finer points of theoretical controversy involved. Ikeda examines the manner in which the two German writers drew upon the writings of James and John Stuart Mill in constructing their conceptions of 'value' and 'good', demonstrating that Rau and Roscher's writings are more systematic in their approach than hitherto assumed. 
The most well-known nineteenth-century instance of German influence on other traditions is that on American economics, which Bradley Bateman examines in his chapter. As is well known, substantial numbers of young American students sought their doctorates in Germany in the last third of the century, but as Bateman points out, this flow was already diminishing in the 1880s as new American universities such as Johns Hopkins offered attractive alternatives. It is therefore important to emphasize that American students of economics came under the influence of the 'Older School' of German Historical Economics, which was primarily interested in the reconstruction of economic theory via a historical appreciation of that theory. Returning students thus brought with them a familiarity with emergent Continental marginalism as well as a historicist inclination, and did not regard the two as being in any way opposed. Bateman goes on to demonstrate that this insight alters our perspective on the development of American economics in the early twentieth century, and shifts the clear emergence of Neoclassicism close to the mid-twentieth century, and not before.

Katia Caldari and Tamotsu Nishizawa consider another aspect of the dissemination of economic ideas - from teacher to student. They consider Alfred Marshall's views on social and economic progress as evidenced by Industry and Trade and his manuscript notes for a planned book: Progress: Its Economic Conditions. They demonstrate that the arguments that he advanced during the last years of his life are continuous with his involvement with progressive associations - related to housing, working conditions and industrial democracy - from the 1880s. However, it was only in his later writings that his ideas were fully articulated and expressed. Marshall's students broadly shared these views, but Sydney Chapman, A.C. Pigou and D.H. MacGregor were of course taught by Marshall during the 1880s and 1890s, when Marshall's ideas in this area had not yet been fully formulated. The Marshallian tradition to whose formation they contributed consequently did not therefore fully reflect what the older Marshall himself thought to be of greatest importance, but instead tended to lay emphasis upon a number of theoretical, rather than ethical, principles.

Michalis Psalidopoulos and Nicholas Theocarakis examine the influence of economic teaching and policy during the formation in the course of the nineteenth century of new countries in South-Eastern Europe with the dissolution of the Ottoman Empire. The path they trace broadly mirrors the political history of Europe in this period: initially French and English liberal ideas had some purchase, although these quickly gave way to protectionist sentiment. The emergence of Germany as a European power in the last third of the century lent German economics, especially the writings of List and Schmoller, a greater profile, and made Germany 
a natural destination for students of economics. However, in the Balkans Russia remained a major influence, and it was from this source that revolutionary ideas regarding agrarian and industrial development were imported, rather than from Germany.

Eyüp Özveren considers the changing reception of three Austrian economists - Schumpeter, Hayek and Polanyi - all of whom lived through the Keynesian Revolution, emigrated to North America, and whose work was more influential and well known in the later twentieth century than it was in the 1950s and 1960s, when a Keynesian synthesis was the dominant international orthodoxy. The Turkish reception of the three Austrians was in two distinct waves, whose ranking changed from one phase to the other. The comparison of Turkey with Japan is motivated by their parallel paths in terms of economic modernization and receptiveness to foreign influences. Hence the way in which the differences between Hayek, Schumpeter and Polanyi have been received in Japan is suggestive of the modernization process in Japan, and hence in Turkey too.

Komine and Masini compare the reception of the writings of Lionel Robbins in Italy and Japan chiefly during the 1930s and 1940s, which implies two separate issues. Firstly, Robbins published during this period his infamous essay on the contemporary depression, his Essay on the Nature and Significance of Economic Science, and a number of texts on the international order and federalism. Secondly, Italy was during the 1930s increasingly corporatist in orientation, while Japan was increasingly ruled by a military clique. It might be thought that the latter would rule out any reception of the former, but they demonstrate that this was far from the case. Partly this was because the local academic culture was not entirely homogenous and closed to outside influence, but also because even those who proved most hostile to Robbins's views - chiefly Marxists - nonetheless had a use for his works as the butt of their criticism.

The contribution of Dimand and Wakatabe focuses on the Kyoto University Economic Review as a medium for communication between Japan and the rest of the world. Founded in 1926 as a semi-annual English-language journal, suspended in 1944 then resuming publication in 1950, the Review provided ready insight into the work of Japanese economists. The Review published translations from a monthly Japanese publication issued by the Kyoto Imperial University Economics Department which reflected the prevailing strong interest in European and American developments, rendering the work of the Japanese economists even more accessible to those outside Japan. While contributions by Japanese economists to international discussion of business cycles, economic growth and of course Keynes's General Theory (1973) were thus made available, in fact little attention was paid to them at the time, and even recent commentators 
on the development of Japanese economics have overlooked this important source.

Ohtsuki devotes his chapter to the way in which empirical methods were introduced at Nagoya University following Akamatsu's return in 1926 from Harvard Business School, where he had encountered both the case study method and early economic research into local industry. This led to study of the local woollen industry and a series of reports, and also to his formulation of a 'flying geese pattern' of economic development moving from the import of finished goods, through the local production of such goods, and then to the eventual development of exports. This was also linked to a theory of long-wave economic development which in the 1930s drew on the work of Kondratiev.

Yagi traces a linkage between three Marxist-oriented institutes in Germany, Japan and Moscow. Starting out from a lecture he attended in 1973 in which Felix Weil talked of the foundation of the Institut für Sozialforschung in Frankfurt, he points out that 'Sozialforschung' was at the time a German neologism, related possibly to the existence of an Institute for Social Research in Japan. The link between the two was provided by Kazuo Fukumoto, a leading Japanese Communist, who possibly suggested the name to Weil when he was casting about for a name that would not arouse the suspicions of the authorities in the University of Frankfurt. From this detective puzzle Yagi develops a fascinating account of the development of Japanese social research, the role of Marxism and the Communist Party, and the common link of both institutes to Rjazanov's Moscow Institute involved in publishing the Collected Works of Marx and Engels.

Finally, Heinz D. Kurz reviews the work of two world-famous Japanese economists, Michio Morishima and Takashi Negishi, demonstrating how their own thinking has developed in dialogue with the 'Western canon', from Adam Smith to Piero Sraffa, competing this volume with a clear example of the impact of Japanese economists on an increasingly international environment.

\section{NOTES}

1. The preparation of this volume was generously supported by a grant from the Japanese Society for the History of Economic Thought, for which the editors are very grateful.

2. The conference was in two parts, meeting on 21-22 March at Hitotsubashi University, Tokyo, and on $24 \mathrm{March}$ at Kyoto University. This was the second such joint conference, the first having been held in Nice in 2006.

3. The European Society for the History of Economic Thought (ESHET) was founded at a meeting in Nice in December 1995, while the Japanese Society for the History of Economic Thought (JSHET) was founded as early as 1950. 
4. The conference topic had been agreed in discussions between Heinz D. Kurz, Tamotsu Nishizawa, Cristina Marcuzzo, then President of the European Society and Tetsuo Taka, then President of the Japanese Society. Five main themes were identified in the call for papers addressed to the international dissemination of economic ideas: (a) the development of economic ideas and their transmission across national borders; (b) the impact of imported ideas upon the framing of responses to perceived domestic economic and social problems; (c) more detailed consideration of policies developed upon this basis; (d) the influence of imported ideas in forming new institutions; (e) identifying three critical episodes in the dissemination period: the Enlightenment, Historicism and the interwar period.

5. Hitotsubashi developed originally from the Commercial Training School founded in 1875 and with an American as its director (Ikema, et al., 2000; 7ff, 32ff)

6. While the United Nations formally came into existence in October 1945, official use of the term to designate the Allied forces dates from the signing of the Atlantic Charter on 1 January 1942.

7. See Carpenter (2002).

8. For example, if you search the Oxford University catalogues for the writings of Karl Marx, the earliest records date from the 1880s and not from the 1840s or 1850s. This is because in such cases libraries reflect the reception and influence of a writer, not his personal publishing history.

9. Akerlof and Shiller's Animal Spirits (2009) misreads Keynes in much the same way that, for example, George Stigler misunderstood Smith's conception of 'self-interest', inverting the original sense. Keynes introduced the idea of 'animal spirits' in the General Theory $(1973 ; 161-2)$ to suggest that humans were prone to act more on impulse than on deliberate reflection. However, the overall argument of the General Theory is directed not to this human propensity to instability, but to the different fact that economies as a whole can become too stable, prone to settle into suboptimal equilibria. Akerlof and Shiller's suggestion that we should instead conceive the inherent instability of economies as rooted in human psychology owes nothing to Keynes, yet by using Keynes's striking phrase claims his reputation.

10. In 2009 four barnacle geese were fitted with satellite transmitters that enabled their wintering flight from Svalbard in the Arctic to the Solway Firth, Scotland to be tracked in real time.

11. Similarly, Schumpeter's Das Wesen und der Hauptinhalt der theoretischen Nationalökonomie was translated into Japanese and published in 1936, but no English version has ever been published.

12. In fact when the Japanese Economic Association was founded in 1934 several historians of economics and of economic thought were founding members; and four from six of those who proposed the foundation of JSHET in 1950 were themselves members of the pre-war Japanese Economic Association.

13. The journal History of Political Economy with an international (Anglo-North American) editorial advisory board was first published in 1969.

14. For an account of the origins of this project, see Claeys et al. (1993).

\section{REFERENCES}

Akama, M. (2000), 'Marxian economics', in A. Ikeo (ed.), Japanese Economics and Economists since 1945, London: Routledge, pp. 123-39.

Akerlof, G. and R. Shiller (2009), Animal Spirits, Princeton, NJ: Princeton University Press.

Carpenter, K.E. (2002), The Dissemination of the Wealth of Nations in French and in France 1776-1843, New York: Bibliographical Society of America. 
Claeys, G., I. Hont, A. Kadish and K. Tribe (1993), 'Editorial Preface: The institutionalization of political economy', in A. Kadish and K. Tribe (eds), The Market for Political Economy: The Advent of Economics in British University Culture, 1850-1905, London: Routledge, pp. viii-ix.

Ikema, M. Y. Inoue, T. Nishizawa and S. Yamauchi (2000), Hitotsubashi University, 1875-2000, Basingstoke: Palgrave.

Keynes, J.M. (1973), The General Theory of Employment, Interest and Money, Collected Writings of John Maynard Keynes Vol. VII, London: Macmillan.

Mizuta, H. (2000), Adam Smith's Library: A Catalogue, Oxford: Oxford University Press.

Nishizawa, T. and A. Ikeo (2008), 'Japan, economics in', in S. Durlauf and L. Blume (eds), The New Palgrave Dictionary of Economics, 2nd edn, Vol. 4, Basingstoke: Palgrave, pp. 603-12.

Sugihara, S. and T. Tanaka (eds) (1998), Economic Thought and Modernization in Japan, Cheltenham, UK and Lyme, NH, USA: Edward Elgar.

Yagi, K. (2000), 'Economics in the academic institutions after 1945', in A. Ikeo (ed.), Japanese Economics and Economists since 1945, London: Routledge, pp. 50-92. 